\title{
Policies for African seed enterprise development
}

\author{
Robert Tripp ${ }^{\mathrm{a}, *}$, David Rohrbach ${ }^{\mathrm{b}}$ \\ a Overseas Development Institute (ODI), 111 Westminster Bridge Road, London SE1 7JD, UK \\ ${ }^{\mathrm{b}}$ International Crops Research Institute for the Semi-Arid Tropics (ICRISAT), P.O. 776, Bulawayo, \\ Zimbabwe
}

Received 14 March 2000; received in revised form 1 November 2000; accepted 14 November 2000

\begin{abstract}
The commercial seed sector has been slow to develop in sub-Saharan Africa. The paper examines the major impediments and identifies areas in which seed policies can be strengthened. Seed enterprise development has been hampered by regulatory frameworks that favor parastatal enterprises and that inhibit commercial innovation. In addition, government and donor projects provide large amounts of free or subsidized seed that further discourages seed enterprise development. In addition to regulatory reform and the curtailment of many seed distribution projects, there are other policy changes that need to be implemented. National agricultural research institutes need to invest more resources in promoting their varieties and helping to stimulate commercial seed production. Greater emphasis is required on regional strategies for public plant breeding and private seed marketing. National policies need to strengthen input marketing capacity and infrastructure. Finally, donors, governments and NGOs should shift from trying to encourage village-level commercial seed production and instead strengthen farmers' capacities to assess new varieties and to be effective consumers of commercial inputs. (C) 2001 Elsevier Science Ltd. All rights reserved.
\end{abstract}

Keywords: Africa; Seed policy; Seed projects; Liberalization

\section{Introduction}

Although commercial seed provision is expanding in most of the world, the story for Africa is very different. With the exception of a few countries (e.g., South Africa),

* Corresponding author. Tel.: +44-20-7922-0300; fax: +44-20-7922-0399.

E-mail addresses: r.tripp@odi.org.uk (R. Tripp), d.rohrbach@cgiar.org (D. Rohrbach). 
and a few crops (e.g., hybrid maize), there is very little evidence of successful commercial seed sector development. This paper examines some of the major reasons for this failure. It also outlines a set of policy changes required to improve the complementarity of public and private sector investments in developing national and regional seed supply systems. Many of the conclusions are based on a recently completed study of seed policies and performance in four countries: Kenya, Malawi, Zambia and Zimbabwe (Tripp, 2000).

The paper argues that the failure of formal seed provision in Africa can be largely attributed to the narrow focus of seed policy regimes. National seed policies emphasize public systems of variety development, multiplication and distribution. Many donor investments target the establishment of community seed projects, subsidize seed delivery or distribute free seed under relief programs. Meanwhile, commercial channels for retail seed trade remain grossly underdeveloped and private seed companies devote their efforts to speculating on the level and timing of the next relief program.

Policy makers are currently under pressure to deregulate and liberalize markets in order to stimulate seed trade. Yet large gaps persist in understanding how public policy can facilitate the development of more sustainable seed supply systems. Deregulation alone will contribute little to the development of seed markets. Institutional development requires a longer term view of development objectives. Particular attention must be directed to the complementarities of public and private investments, and towards the linkages between various levels of seed production - from breeding to commercial seed delivery.

This paper examines these issues in the context of a review of recent investments in seed projects by a range of donors in Africa. The first three sections describe the principal impediments to seed system development: seed regulatory regimes, national seed production agencies and seed distribution programs. The following three sections examine opportunities for the pursuit of more complementary investments by: national agricultural research institutes, commercial seed companies, and community seed projects. The final section draws conclusions and outlines the requirements for seed policy reform in Africa.

\section{Regulation}

Most African countries share a common seed provision strategy. Public agencies are responsible for developing, multiplying and distributing seed of new varieties. Strict controls on variety release, multiplication and trade are viewed necessary to protect the farmer. As a result, virtually all plant breeding is in the hands of publicly funded national agricultural research institutes (NARIs). A single agency is given responsibility for formal seed production under the regulatory control of a national seed laboratory or quality control unit.

Seed regulations have developed to support this system, and, it may be argued, to protect these monopolies from outside competition. Thus only seed of varieties that have been approved by the official variety release committee can be sold. These 
committees have historically been controlled by public sector officials and scientists who look with suspicion on foreign varieties. Selection criteria have emphasized grain yields documented in government-run trials. In most cases, seed certification has been mandatory. Quality control standards are enforced by a national seed laboratory and certification agency with only a single client, the national seed company.

During the past ten years liberalization policies, the failure of many parastatal seed companies, and the weakening support for NARIs have caused this general model of seed regulation to be questioned throughout the continent. These concerns have been reinforced by the recognition that variety adoption continues to lag for most crops other than maize. Yet uncertainty remains about how much regulation is necessary to protect the small-scale farmer. In consequence, the extent of actual reforms has generally been superficial.

With respect to variety release, some countries (such as Zambia) have established fairly transparent procedures for testing and approving foreign varieties. But progress is slow; it has taken many years for Kenya to begin to allow the sale of foreign maize hybrids. In the majority of cases the variety release procedures still work in favor of those varieties developed by the NARI. Varieties released by NARIs in neighboring countries, or those developed by private companies, face an uphill battle for approval. The results of privately run trials or trials in neighboring countries with similar agro-ecologies are not considered. Also, the relative importance of traits other than yield, such as improvements in processing quality valued by industry, still receive little or no consideration.

Similarly, reforms of seed quality and certification regulations have generally resulted in only cosmetic change. Recent modifications in Zimbabwe and Malawi have allowed seed of certain crops to be sold without certification. This is largely because public certification agencies acknowledged they did not have the funding or staff to assure certification regulations were consistently implemented. However these countries still require that all seed must be tested for germination and purity by an official laboratory. A few larger companies have been permitted to maintain licensed laboratories, but seed from other producers must still pass through a government testing facility before it can be marketed.

Although there is considerable discussion about the harmonization of seed laws (e.g., Commonwealth Secretariat, 1994), only in the past year have there been renewed discussions about possible harmonization strategies in eastern and southern Africa. Harmonization is viewed by seed companies as a means to facilitate regional trade of seed. Some regulators in government seed units, however, view harmonization as a means to reinforce strict rules relating to phytosanitary standards and seed purity. In effect, harmonization could lead either to a reduction of non-tariff barriers to trade, or to the common enforcement of stricter national rules. One key decision relates to the possibility of a regional agreement on variety release or registration. Most countries remain reluctant to give up strict controls on variety release, yet the demand for most nationally registered varieties remains insufficient to encourage commercial investments in seed multiplication and distribution. A recent analysis has demonstrated the potential for grain trade within Eastern and Southern Africa (Weeks and Subasat, 1998). A similar potential exists for regional seed trade (Rusike 
and Rohrbach, 1998). Yet there have been only preliminary discussions of requisite moves towards regional registration of varieties, or the possible elimination of registration requirements.

Similar uncertainty underlies requirements for seed trade within most countries. Though competition is now being allowed with government seed enterprises, and some of these public companies are being privatised, wholesale and retail traders in most countries must still obtain special licenses to sell seed. Regulations ostensibly meant to restrict sales of inappropriate seed severely limit the extent of participation in seed trade. Regulators rarely have the capacity to carry out point-of-sale inspection and farmers, whom the licensing restrictions are meant to help, remain with no access to improved varieties.

\section{Public seed production agencies}

Another impediment to sustainable seed provision in Africa is the continuing existence of inefficient public seed production agencies. A number of parastatal seed companies are still in operation, although some of these have been closed (e.g., Ghana) or sold off (e.g., Malawi). Until recently, many of these parastatals have enjoyed a monopoly status, discouraging the formation of domestic private seed companies and blocking the entry of foreign firms. This situation is now changing, but private seed companies still operate at a considerable disadvantage.

Some countries maintain national seed multiplication units rather than parastatal seed enterprises. The range of seed crops multiplied by such units is limited and the costs of multiplication and distribution are high. We have no examples of full cost recovery for any of these operations. In Botswana, for example, virtually all of the seed 'sold' by the national Seed Multiplication Unit is delivered to national drought relief programs. Further, the cost of seed produced by contract farmers is higher than the price of the limited quantities of seed sold through commercial channels (Rohrbach and Makhwaje, 1999). Recent studies in West Africa (Ndjeunga, 1997) reveal that most public seed multiplication units and laboratories are largely defunct, despite donor investments of more than US\$100 million in their development. Trained staff move on to more remunerative positions, laboratories are not maintained, seed production estimates are grossly inaccurate, seed production costs are higher than sales revenues, and farmers remain largely unaware of most new varieties.

\section{Seed distribution programs}

One of the most serious constraints to seed system development is the strategy of free seed distribution, either through relief operations, or in the context of agricultural development programs. During the past decade, serious droughts, wars and civil conflict have been the motive for a number of emergency seed distribution efforts. Governments and NGOs search for whatever seed inventories they can find on 
regional and global markets to meet this demand. The sudden need for large quantities of seed, often declared just weeks before the next planting season, almost inevitably leads to the purchase of poor quality seed of inappropriate or unidentified varieties (ODI Seeds and Biodiversity Programme, 1996). Regulations restricting sales of unreleased varieties, or seed of unknown quality, are simply ignored in these cases.

In many countries, free seed deliveries have continued even after the end of relief programs. The political value attached to handing out free agricultural inputs has encouraged a proliferation of government, donor and NGO programs delivering seed as part of more general poverty alleviation strategies. Recent experience in Malawi provides a good example (Table 1). A severe drought during the 1991/92 season led to a large-scale distribution of maize 'seed' (actually locally purchased grain) in 1992/93. This was followed by the distribution of hybrid seed and fertilizer in subsequent seasons. Continuing concern about food shortages and the low adoption of hybrid seed and fertilizer led to a joint donor-government 'Starter Pack Scheme' in 1998/99. This program distributed 2.6 million packs of free (mostly hybrid) maize seed, a legume 'seed' (mostly obtained in grain markets), and fertilizer (enough to plant 0.1 ha for every farm household in Malawi). The scheme was repeated in 1999/2000. The scheme is defended both as a means to help rural Malawians make up for production shortages and as an extension tool to introduce farmers to modern inputs.

A similar story can be told for Zimbabwe (Table 2). After a drought-induced seed distribution program in 1992/93, the government continued distributing seed of various crops and fertilizer as a poverty alleviation measure for an additional five years. Following the 1991/92 drought, the government and various relief agencies distrib-

Table 1

Seed distribution in Malawi: some major examples ${ }^{a}$

\begin{tabular}{ll}
\hline Program & Activities \\
\hline $\begin{array}{l}\text { Drought Relief Seeds Distribution Project, } \\
1992 / 93\end{array}$ & $\begin{array}{l}\text { In response to drought of 1991/92, 1.3 million } \\
\text { farmers each received 10 kg of maize 'seed', } \\
\text { purchased on local grain market } \\
\text { In response to uneven rains the previous year, and } \\
\text { collapse of the agricultural credit system, } 4139 \mathrm{t} \\
\text { of hybrid maize seed was distributed to farmers } \\
\text { 3451 t of hybrid maize seed and 21 t of sorghum } \\
\text { seed distributed. Fertiliser distributed in higher- } \\
\text { potential areas } \\
\text { Hybrid maize seed, fertiliser and legume seed } \\
\text { sufficient for planting 0.1 ha distributed to every } \\
\text { farm household in Malawi (2.6 m packs). Total } \\
\text { seed distribution 5200 t hybrid maize, 500 t OPV } \\
\text { maize, 4000 t groundnut, 1600 t soybean } \\
\text { Starter Pack Scheme repeated for second year. }\end{array}$ \\
\hline
\end{tabular}

\footnotetext{
a Source: Longley et al. (1999).
} 
Table 2

Zimbabwe: government investment in seed distribution programs, 1992/93 to 1998/99 (Z\$million) ${ }^{\mathrm{a}}$

\begin{tabular}{ll}
\hline Cropping season & Expenditure on seed distribution $^{\mathrm{b}}$ \\
\hline $1992 / 93$ & 71.4 \\
$1993 / 94$ & 29.9 \\
$1994 / 95$ & 43.5 \\
$1995 / 96$ & 87.2 \\
$1996 / 97$ & 65.0 \\
$1997 / 98$ & $24.5^{\mathrm{c}}$ \\
$1998 / 99$ & $17.1^{\mathrm{c}}$ \\
\hline
\end{tabular}

a Sources: Mukora (1997); National Early Warning Unit (1999).

b Cost of seed only (maize, sorghum, pearl millet, groundnut and sunflower); does not include distribution costs.

c Costs of vouchers distributed to farmers to subsidize purchases of seed and fertilizer.

uted enough sorghum and pearl millet seed to cover 20-30 percent of the national acreage planted to these crops (Friis-Hansen and Rohrbach, 1993). In the 1993/94 cropping season enough sorghum seed was distributed to plant 150\% of Zimbabwe's sorghum area (and enough pearl millet seed for $80 \%$ of the crop's area) (Rohrbach et al., 1997). The government curtailed the input distribution program after 1997/98, but replaced this with a new program to distribute vouchers that could be exchanged for seed.

Such seed distribution programs have a predictable impact on the seed industry. Although the programs have increased industry interest in crops such as sorghum, pearl millet and grain legumes, companies remain reluctant to invest in producing quality seed of released varieties of these crops due to uncertainty about the consistency of seed demand. This concern is reinforced by the fact that some tenders are awarded for cheaper generic seed (or grain cleaned to seed standards) rather than higher quality seed stocks of specific new varieties. Correspondingly, farmers complain that they already have the varieties being distributed through relief programs. In some cases, grain that farmers have sold has been returned to them as seed (Rohrbach and Mutiro, 1997).

Seed distribution programs have also discouraged the development of wholesale and retail seed trade channels (Tripp, 2000). Companies are pleased to sell large consignments of seed to a single buyer. Any interest in developing local seed distribution channels is reduced by the possibility that government or an NGO will suddenly initiate a free seed distribution program.

The disincentives and uncertainty caused by seed distribution programs, the inefficiencies and privileges of public seed producers, and the existence of restrictive regulatory regimes all conspire to inhibit the development of a commercial seed sector in Africa. Policy change is required to address each of these problems. In addition, attention must be given to three other areas: the interface between public plant breeding and the commercial seed sector, strategies that encourage the emergence of commercial seed capacity, and the orientation of local-level seed projects. 


\section{National agricultural research institutes}

The absence of effective formal seed systems in Africa greatly reduces the impact of publicly funded plant breeding programs. Failures of seed multiplication and dissemination translate into negative rates of return to research investments. NARIs have been let down by ineffective and under-funded extension services (who are supposed to promote these varieties) and by inefficient parastatal seed companies that never managed to deliver seed for many crops that are important to African farming systems. While NARIs cannot be blamed for these failures, they have no other choice than to accept major responsibility for addressing the problems. One consequence is that NARIs must accept more of a stewardship role for their research results. This may require reallocating funds away from the development of additional varieties towards the monitoring of breeder, foundation and commercial seed production of varieties already released. Part of this funding may also need to be allocated to programs specifically designed to increase public awareness about new varieties. These additional responsibilities are admittedly difficult in an era of restricted funding for NARIs, but unless they are able to play a stronger role in delivering their products, the funding scenario will only grow darker.

Currently, most African farmers know little about the range of plant varieties being developed and released by national crop improvement programs. It is not unusual to find that the farmers growing a new variety do not even know its name (Tripp, 2000). Varieties distributed in relief programs are locally named for their characteristics or for the extension worker responsible for introducing this seed to a community. Recent ICRISAT surveys in Zimbabwe, for example, indicate that new sorghum and pearl millet varieties introduced in 1992 commonly have 4 to 8 different names depending on the circumstances of initial delivery.

While ignorance of the official name of a variety is not a major problem per se, given the convoluted letter and number codes often assigned to varieties (and the problems of choosing which local language to use), greater knowledge of variety options can facilitate decisions about adoption. Farmers may justifiably ask whether the new variety of pearl millet being introduced this year is the same cultivar they already have, or the same poor variety they received during a previous drought relief program, or something truly new. The success of those varieties that have spread from farmer to farmer is often based on an immediately obvious characteristic, such as early maturity. If NARIs hope to offer a range of varieties of one crop, or to improve upon available varieties with new cultivars offering more cryptic qualities, such as disease resistance, then more must be invested in ensuring that farmers can appreciate what is on offer.

Similarly, variety promotion needs to become more imaginative. In an age of falling communication costs (and increasing literacy), the provision of simple, attractive printed material that describes new varieties should be pursued. Farmers also need more information about where to find seed of new varieties - assuming this is available on the market. In recent surveys in Zimbabwe, most farmers had no idea where to find seed of new varieties for most crops other than hybrid maize (Rohrbach, 1997). Once seed became available in local retail shops, demand sharply 
increased (Rohrbach and Malusalila, 1999).

One strategy that has proven useful for disseminating information about varieties, and demonstrating commercial viability of seed demand, is the production and sale of small packs of seed of new cultivars. The strategy was pioneered by CIAT (International Center for Tropical Agriculture) and the national bean research programs in several African countries. In Malawi, the Bean Improvement Program (BIP) has managed the production and sale of small packs $(0.5 \mathrm{~kg}$ or less $)$ of seed of six new bean varieties. The packs have been sold by rural merchants and grocery shops (as well as NGOs and extension offices). Over a period of three years, more than 15 tons of seed were sold in this way, and both merchants and farmers are enthusiastic about the experience (Phiri et al., 1999). Such public investments in demonstrating the demand for new varieties should help stimulate commercial investments in multiplying and distributing this seed.

Another problem is the failure of NARIs to maintain basic stocks of breeder and foundation seed. Seed provision depends on a well-organized source seed system in which the original seed is multiplied through a series of stages to obtain sufficient commercial seed. The nomenclature varies among countries, but for our discussion breeder seed is the pure line maintained by the breeder, and foundation seed is the penultimate stage planted to obtain commercial seed. Breeder seed maintenance is often not separately funded in the budgets of NARIs. Breeders must decide how much to invest in seed production versus further breeding activities. As incentive systems reward additional releases, rather than seed availability and adoption, multiplication efforts emphasize the maintenance of small quantities of seed for the breeders' own use. Yet even this task is problematic given limited national investments in maintaining research stations, irrigation facilities and cold stores. International Agricultural Research Centers (IARCs) commonly receive annual requests from poorly endowed NARIs for the same germplasm.

In many African countries, foundation seed production has historically been the duty of a national seed company with exclusive rights to public varieties. But if a competitive commercial seed system is to be established, there must be open access to foundation seed of new varieties. In order to promote this transition, NARIs must give higher priority to breeder seed production. In addition, they must invest resources in the production and distribution of foundation seed. This task may be performed either by the research institute itself, or by individuals or companies contracted to pursue the job.

Increased attention to source seed production should not be confused with income generation. Many NARIs, encouraged by donors promoting the 'privatization' of public research, have come to believe that they can earn a significant income from royalties on public varieties. However, this premise is largely unwarranted for African NARIs. In the first place, the amount of money to be earned from potential royalties on most crop varieties is very modest. Secondly, given the underdeveloped state of the commercial seed industry in Africa, this proposition puts the cart before the horse. Perhaps most important, concentration on commercially attractive research negates the justification for funding NARIs in the first place. "If the sale of research 
products is feasible and profitable, why should the public sector be involved in the research in the first place?" (Byerlee and Alex, 1998 p. 37).

Finally, NARIs need to spend more time, and even a share of their budget, working with seed companies to encourage multiplication and sale of their latest varieties. In most African countries, public breeders still view themselves in competition with private breeders. Yet this is a competition they are unlikely to win. Instead, NARIs should openly acknowledge the evolutionary nature of this relationship (Pray and Ramaswami, 1991). Companies may start by multiplying varieties developed by the public sector. But over time, these companies can be expected to develop their own variety selection and breeding programs. NARI breeders may then aim to fill gaps in germplasm supply or variety targeting - for example the continuing supply of open pollinated varieties. Regardless of the stage of development, greater collaboration between NARIs and seed companies will improve the likelihood that the results of public breeding programs will reach farmers.

\section{Commercial seed development}

Although current regulations and seed distribution programs limit the development of commercial seed sectors, it would be misleading to give the impression that Africa is full of potential entrepreneurs waiting for the green light of seed policy reform. The seed business is full of risks, and there are many uncertainties about the potential level of seed demand in Africa.

There are a few obvious success stories for commercial seed in Africa. The most prominent example is the sale of hybrid maize. In Zimbabwe and Kenya, 68\% and $52 \%$, respectively, of the area planted to maize is sown to hybrid seed (CIMMYT, 1999). South Africa has a strong and competitive seed sector built around the supply of hybrid seed for maize, sorghum and sunflower.

Yet a stable and commercially viable hybrid seed sector remains a characteristic of only a handful of countries. Several multinational seed companies have entered national markets only to retreat after a few years of disappointing sales. In many of these cases, farmers have simply not been willing to pay the high seed prices ( 7 to 10 times the grain price) characteristic of hybrids. Despite the privatization of the national seed company in Malawi, and the development of several attractive new maize hybrids, only a minority of farmers are regular purchasers of hybrid seed in this country (Smale and Phiri, 1998).

Nonetheless, recent research evidence suggests that commercial seed demand has been underestimated. First, it is important to correct the myth that virtually all of the seed used in Africa, of crops other than hybrid maize, is farm-saved. The degree to which farmers save their own seed varies widely, depending on the crop and the farming conditions. As a rough estimate, at least 20 to 30 percent of the non-commercial seed used by African farmers is acquired off-farm (Tripp, 2000). The most frequent reason for obtaining fresh seed is to make up for a poor harvest. Seed stocks may be consumed before planting time, or sold by families desperate for cash. Yet the decision to dispose of these stocks is made with knowledge that seed is likely 
to be available from neighbors or nearby traders at the beginning of the next planting season.

Studies of seed market activity in southern and western Africa show that the majority of small-scale farmers participate in acquiring or providing seed in any given year (Rohrbach, 1997; Ndjeunga, 1999). Many of these transactions take the form of gifts or barter. However, a significant proportion of seed is also annually purchased for cash, from other farmers or grain markets. Such purchases are common among virtually all types of farmers. Although this 'seed' is usually purchased for the prevailing grain price, companies need to recognize that such prices rise considerably at planting time. Farmers are often paying close to what a well-run commercial enterprise could charge for non-hybrid seed (i.e., 2 or 3 times harvest grain price).

An experimental program in Zimbabwe aimed to challenge the perception of both seed companies and rural retail traders that once farmers obtain seed of a given open- or self-pollinated variety, they will not return to the market to purchase fresh seed (Rohrbach and Malusalila, 1999). The Seed Company of Zimbabwe worked with ICRISAT to test the demand of small-scale farmers by selling small packs of sorghum, pearl millet, groundnut and sunflower seed through rural retailers. The seed was priced at full commercial levels. Despite the late delivery of the stocks, virtually all of the seed was sold, and the Seed Company of Zimbabwe quickly agreed to expand the scheme the following season. The Seed Company has also encouraged a sister institution, Sementes de Mocambique (the national seed company in Mozambique) to establish the program in three provinces of that country. Retail stockists were similarly enthusiastic to participate in this program during the 1999/2000 planting season.

Yet the development of this market remains an uphill battle. Much of the Seed Company of Zimbabwe's packing capacity for small packs of seed was unexpectedly committed until late in the planting season to meet contracts to supply seed for Malawi's 1999/2000 “Starter Pack Program”. As a result, efforts to evaluate the size and consistency of commercial seed demand in both Zimbabwe and Mozambique have had to be postponed for a year.

The limited strength of retailing capabilities for agricultural inputs, including seed, remains an important problem. More than a decade ago, Shepherd (1989) warned that the liberalization of fertilizer markets in Africa would not lead to a great increase in sales unless attention was given to the financial and technical capacities of stockists. That judgement is still relevant today for both fertilizer and seed marketing networks. Most rural retailers survive on the basis of rapid turnover of limited capital obtained through the sale of commodities for which demand is well known. These traders are reluctant to risk their scarce capital stocking commodities such as seed, for which demand is less certain. Thus, initial market development investments are required to prove the level and consistency of seed demand. If seed system development is to be sustainable, larger efforts will be required to build local marketing institutions.

Another lesson from recent seed studies in Africa is the opportunity for linking seed provision with the development of product markets. The demand for improved varieties of pigeonpea in Kenya and Tanzania has been linked with the growing 
demand for grain for export to India and Europe (Jones et al., 1999). In Kenya, a seed company has recently initiated pigeonpea seed production in response to demand from several NGOs interested in promoting the commercialisation of the crop. A grain trader in northern Tanzania has initiated seed sales to farmers from whom he purchases pigeonpea grain.

Unfortunately, there are relatively few examples of successful efforts to link seed sales with the development of product markets in Africa. One problem is that grain marketing itself has been historically controlled by the government, and premiums for grain quality (that might lead to demand for better seed) are rarely in evidence. Another problem is the high transaction costs (and slow development of trust between merchants and farmers) in many cash cropping situations. These costs are multiplied when companies or traders must work with larger numbers of dispersed and relatively isolated small-scale farmers. A study by Dorward et al. (1998) illustrates how these problems affect the provision of cotton seed in Ghana and cashew seed in Tanzania.

\section{Local-level seed projects}

In the past decade, many donors and policymakers have promoted the development of community-level seed enterprises as an alternative source of seed for non-hybrid varieties (Wiggins and Cromwell, 1995). There have been a large number of projects in Africa, Asia and Latin America that have pursued this goal. The strategies have varied, but many projects in Africa follow a similar pattern: NGO or project staff organize farmers in a village who wish to be seed producers; in the majority of cases the farmers are encouraged to work as a group. The farmers are loaned source seed (usually acquired from the NARI) of one or more new crop varieties. They are expected to multiply this seed, and to repay the loan with fresh seed to be allocated to a new set of farmers. These nascent entrepreneurs are provided with training in seed multiplication techniques and often some kind of quasi-certification is provided by staff of the regulatory agency or by extension agents who are deputed as seed inspectors. The farmers are then expected to use part of the seed on their farms, and to sell the rest to neighboring farmers. The theory is that this activity will evolve into a financially viable village-level enterprise.

There is now enough experience with these projects to develop some general conclusions about their performance. In a number of cases, they have been quite effective at expanding farmers' access to seed of new varieties. The seed has diffused well beyond the participating farmers and often to other villages. But this diffusion has taken place through the normal channels of seed exchange between households; the seed is either provided as gifts, or is sold at the price of grain. We know of no case where a sustainable small-scale seed enterprise has emerged from this type of activity. The reasons are fairly obvious.

In the first place, there is simply not sufficient demand at the individual village level to maintain a commercial seed enterprise, and farmer seed producers usually have few contacts outside their villages. A few projects have resolved this constraint 
by collecting seed for ad hoc sale to government or NGO-supported relief and development programs. However, this strategy is unsustainable in the long run. None of these projects have developed retail trading networks.

The attainment of cost recovery is complicated by the inability of neighboring farmers to acknowledge any added value of seed produced in this way. Farmers see little reason to start paying their neighbors a premium for locally-produced seed. If the full costs of source seed, seed inspections and advisory services are included, the probability of maintaining a financially viable enterprise after the termination of project support is very low.

One example of small-scale seed production that has had greater success provides a contrast to the strategy described above. In Ghana, individual farmers (often former contract growers for the defunct national seed company) have been recruited and trained to multiply seed of open-pollinated maize varieties. The growers buy foundation seed from a government agency, multiply it, and pay for conditioning and storage (at the former seed company's facilities). The growers are responsible for selling their seed to input dealers; these dealers usually buy seed from several different growers. The dealers may help finance the seed multiplication and storage, and the growers in turn often agree to be paid for their seed after it has been sold (Lyon and Afikorah-Danquah, 1998). The system is far from perfect, as it relies on access to former parastatal processing and storage facilities, and on the administration of quality control by an under-funded regulatory agency. But at least it is based on a transparent system of access to source seed and processing facilities and uses the commercial experience and financing of established input dealers.

\section{Seed policy reform}

Policy reform must start with a re-examination of the objectives of seed system development, and a diagnosis of problems still limiting the delivery of high quality seed to most farmers. Seed systems emerge in response to investment incentives and consumer demand. In many countries the underlying conditions for investment and the articulation of demand need to be strengthened.

Policies need to envision complementary roles for the public and private sectors, recognizing that these will evolve with time. In the short term, a larger share of public research budgets needs to be allocated to the technology transfer activities necessary to justify past investments in variety development. A well functioning NARI should be capable of promoting the adoption of useful crop varieties, as well as developing them. In pursuing this objective, NARIs ought to become more proactive in advertising new varieties and promoting commercial seed production and sale. A more aggressive NARI role presumes a concerted donor effort in supporting public agricultural research as well as the development of national political will to put NARIs on a firm footing. Unfortunately, neither prospect is currently very bright.

Seed sector development policies should also aim to reduce chauvinism in variety testing and release. National varieties (like national airlines) are a source of pride, but are often an inefficient luxury. For many crops, in many countries, there is simply 
not sufficient demand to justify independent breeding programs. Seed policies should explicitly encourage regional releases and regional variety registration. Emphasis can then be placed on encouraging seed companies to pursue regional markets, and providing farmers larger sets of variety choices.

Correspondingly, policies targeting the development of the private seed sector should also promote a regional approach. In the short term private investment will be motivated more by the prospect of regional markets than by small national markets. The success of harmonized seed laws ought, then, to be measured in the growth of regional seed trade.

Special incentives are required to encourage investment in the development of seed marketing channels extending deeper into rural areas. For those crops for which there is a clear commercial demand for particular varieties, more support can be given to helping link output markets and input supply. Credit and business training may be earmarked for small-scale rural retailers willing to stock a wider range of agricultural inputs. Publicly funded extension support can more directly promote experimentation with new agricultural inputs. Over time, as farmers become accustomed to buying seed, or at least looking for new varieties, public interventions can be reduced.

Donors and NGOs, as well as policymakers, should think more carefully about what types of community level activities are most likely to stimulate seed system development. There is now good evidence that, despite its attractive image, the strategy of village-level seed enterprises is untenable. Part of the problem is mistaking seed multiplication (which all farmers are capable of) for the more complex process of market development. Community seed projects may achieve a greater impact by strengthening the capacities of farmers to test new varieties and to make them wellinformed consumers of agricultural inputs. Local-level interventions should also develop farmers' crop marketing capacities.

Policymakers also face some difficult choices regarding the future of current seed regulatory regimes. Regulatory systems and institutions feature mixtures of good intentions and entrenched interests. Regulation ought to become more of a shared responsibility of seed producers, seed consumers, and a third party agency (Tripp and Louwaars, 1997). In most African countries, the current balance over-emphasizes the government regulator. There is little evidence that mandatory certification and testing has substantially benefited most farmers. Such regulations have probably constrained the distribution of new varieties. A more iterative and experimental approach to seed regulation seems to be needed. Seed regulatory agencies may provide a more positive contribution to market development by shifting their emphasis to consumer education and to point-of-sale inspection in order to strengthen the farmers' side of the regulatory equation.

Finally, more coherent national seed policies with specific impact objectives are required. In the past, it has been too easy for policymakers and donors to address seed development with a series of disconnected, often inconsistent, projects. These offer an attractive way for donors to spend their budgets. They often contribute an appealing community-level focus, but they rarely pay any attention to the long-term strategies of sectoral development. Recent experiences suggest there is no simple 
formula for seed system development. But they also reveal the importance of ongoing monitoring of the impacts of new investments, an evolution in the roles of the public and private sectors, and an agreement about both short and medium terms goals for seed system development.

\section{Acknowledgements}

The authors are grateful to the Competitive Research Facility of the UK Department for International Development (DFID) for supporting some of the research presented in this paper. The comments of two anonymous reviewers were also useful. The conclusions are the authors' and do not necessarily reflect the opinions of ICRISAT, ODI or DFID.

\section{References}

Byerlee, D., Alex, G., 1998. Strengthening National Agricultural Research Systems: Policy Issues and Good Practice. World Bank, Washington, DC.

CIMMYT, 1999. CIMMYT 1997/98 World Maize Facts and Trends. CIMMYT, Mexico, DF.

Commonwealth Secretariat, 1994. Harmonization of Seed Laws in the SADC Region. Commonwealth Secretariat, London.

Dorward, A., Kydd, J., Poulton, C. (Eds.), 1998. Smallholder Cash Crop Production under Market Liberalisation. CAB International, Wallingford, UK.

Friis-Hansen, E., Rohrbach, D., 1993. SADC/ICRISAT 1992 Drought Relief Emergency Production of Sorghum and Pearl Millet: Impact Assessment, ICRISAT Southern and Eastern Africa Region Working Paper 93/01, ICRISAT, Bulawayo.

Jones, R.B., Freeman, H.A., Londner, S., 1999. Improving the Access of Small Farmers in Africa to Global Markets Through the Development of Quality Standards for Pigeonpea. Paper presented at the conference, Markets, Rights and Equity: Rethinking Food and Agricultural Standards in a Shrinking World, Michigan State University, Oct. 31-Nov. 3, 1999.

Longley, C., Coulter, J., Thompson, R., 1999. Malawi Rural Livelihoods Starter Pack Scheme, 1998-9: Evaluation Report, Unpublished Paper, ODI, London.

Lyon, F., Afikorah-Danquah, S., 1998. Small-Scale Seed Provision in Ghana: Social Relations, Contracts and Institutions for Micro-Enterprise Development. Agricultural Research and Extension Network Paper No. 84, ODI, London.

Mukora, C., 1997. An Evaluation of the Crop Pack Programme: 1992-1997. Working Paper 18, Economic Advisory Project, Harare: Friedrich-Ebert-Stiftung.

National Early Warning Unit, 1999. Monthly Food Security Bulletin, December 1998, Vol. 12. National Early Warning Unit, Harare.

Ndjeunga, J., 1997. Constraints to variety release, seed multiplication, and distribution of sorghum, pearl millet and groundnut in Western and Central Africa. In: Rohrbach, D.D., Bishaw, Z., Van Gastel, A.J.G. (Eds.), Alternative Strategies for Smallholder Seed Supply: Proceedings of an International Conference on Options for Strengthening National and Regional Seed Systems in Africa and West Asia, 10-14 March 1997, Harare, Zimbabwe. ICRISAT, Patancheru, India, pp. 34-46.

Ndjeunga, J., 1999. Comparative Analysis of Seed Systems in Niger and Senegal. Niamey, ICRISAT. (unpublished report).

ODI Seeds and Biodiversity Programme, 1996. Seed Provision after Disasters, Relief and Rehabilitation Network Good Practice Review No. 4, ODI, London.

Phiri, M.A.R., Chirwa, R., Kandoole, S., Tripp, R., 1999. Introducing new bean varieties with small seed 
packs: experience from Malawi. ICRISAT and ODI 'Linking Seed Producers and Consumers Project' (unpublished paper).

Pray, C., Ramaswami, B., 1991. A Framework for Seed Policy Analysis in Developing Countries. IFPRI, Washington, DC.

Rohrbach, D.D., 1997. Farmer to farmer seed movements in Zimbabwe: issues arising. in alternative strategies for smallholder seed supply. In: Rohrbach, D.D., Bishaw, Z., Van Gastel, A.J.G. (Eds.), Proceedings of an International Conference on Options for Strengthening National and Regional Seed Systems in Africa and West Asia, 10-14 March 1997, Harare, Zimbabwe. ICRISAT, Patancheru, India, pp. 171-179.

Rohrbach, D.D., Mutiro, K., Mazhangara, E., 1997. Seed availability and markets: the case of sorghum and pearl millet seed supply in Zimbabwe. In: Proceedings of the Zimbabwe National Sorghum/Millets Program Workshop: Formation of a national sorghum and millets coordinating committee and strategies for ensuring good quality seed for smallholder farmers through coordinated research and extension, 18-19 February 1997, Harare, Zimbabwe. Department of Research and Specialist Services, Harare, pp. 52-76

Rohrbach, D.D., Mutiro, K., 1997. Formal and informal channels of sorghum and millet seed supply in Zimbabwe. In: Proceedings of the workshop on seed policies in Zimbabwe: an agenda for action, 3031 July 1996, Harare, Zimbabwe. Environment and Development Activities, Harare, Zimbabwe, pp. $39-47$

Rohrbach, D.D., Makhwaje, E., 1999. Adoption and Impact of New Sorghum Varieties in Botswana. ICRISAT, Bulawayo, Zimbabwe. (semiformal publication).

Rohrbach, D.D., Malusalila, P., 1999. Developing rural retail trade of seed through small packs. ICRISAT and ODI 'Linking Seed Producers and Consumers Project' (unpublished paper).

Rusike, J., Rohrbach, D., 1998. Seed stocks of maize, sorghum, pearl millet, groundnut, pigeonpea and cowpea in Southern African Development community countries. ICRISAT, Bulawayo, Zimbabwe.

Shepherd, A., 1989. Approaches to the privatization of fertilizer marketing in Africa. Food Policy 14, $143-154$.

Smale, M., Phiri, M.A.R., 1998. Institutional Change and Discontinuities in Farmers' Use of Hybrid Maize Seed and Fertilizer in Malawi: Findings from the 1996-97 CIMMYT MoALD Survey, Economics Working Paper 98-01, CIMMYT, Mexico, DF.

Tripp, R., 2000. Strategies for Seed System Development in Sub-Saharan Africa: A Study of Kenya, Malawi, Zambia and Zimbabwe. ICRISAT Working Paper Series No. 2. ICRISAT, Bulawayo, Zimbabwe.

Tripp, R., Louwaars, N., 1997. Seed regulation: choices on the road to reform. Food Policy 22, 433-446.

Weeks, J., Subasat, T., 1998. The potential for agricultural trade among Eastern and Southern African Countries. Food Policy 23, 73-88.

Wiggins, S., Cromwell, E., 1995. NGOs and seed provision to smallholders in developing countries. World Development 23, 413-422. 